\title{
Weather, Mood and Stock Market Returns in Argentina
}

\author{
Bakri Abdul Karim ${ }^{1}$, Muhammad Hafiz Mohd Shukri ${ }^{1} \&$ Sharon Tay Chyu Yuin ${ }^{1}$ \\ ${ }^{1}$ Faculty of Economics and Business, Universiti Malaysia Sarawak (UNIMAS), Kota Samarahan, Sarawak, \\ Malaysia. \\ Correspondence: Bakri Abdul Karim, Faculty of Economics and Business, Universiti Malaysia Sarawak (UNIMAS). \\ E-mail: akbakri@unimas.my
}

Received: October 3, 2018

Accepted: November 14, 2018

Online Published: November 20, 2018

doi:10.5430/afr.v7n4p159

URL: https://doi.org/10.5430/afr.v7n4p159

\begin{abstract}
The paper examines the relationship between weather and stock market returns in the Argentina's stock market using daily data from 2001 to 2014 and regression models. The data consists of stock market returns, temperature, humidity and wind. The empirical findings show that all weather variables (temperature, humidity and wind) have significant relationship with stock market returns in some of the trading days in the week. We also find evidence of the existence of day-of-week effect in the stock market. On average, the highest return falls on Friday and lowest return falls on Monday. Temperature is considered very significant in influencing the stock market returns in Argentina. Our findings suggest that the stock market returns are higher when the temperature is higher. This phenomenon is related to the seasonal affective disorder (SAD). We can conclude that stock market of Argentina is not informational efficient. The results have major implications for traders, individual investors, fund managers and financial institutions to make investment planning in the Argentina's stock market.
\end{abstract}

Keywords: weather, investors' mood, stock returns, Argentina

\section{Introduction}

Psychologists have proven that sunlight affect people‘s moods, thinking, judgment and decision-making. There are numerous studies conducted on the impact of weather on mood and decision making. Chang et al. (2006) argued that weather is an important factor that may affect human moods, and thus may affect investors' behavior in the stock market. In addition, Howarth and Hoffman (1984) have shown that human become more optimistic when exposed to sunshine. In addition, Isen (2000) pointed out that human perform better in creative problem solving in a good mood. However, Sinclair and Mark (1995) have argued on the downside of a good mood is less evaluation and analysis are made on the information provided and eventually lead to a less accurate decision making. Weather is believed to have an impact on investors' mood which will obstruct their decision making. When an investor is affected by the weather, either they are in a good mood or bad mood, it affects their decision in the buying or selling decision. Later the investor's decision influences the fluctuation of the stock market prices. For example, Brahmana et al. (2014) found that on average, Monday has a higher temperature as compared to other days-of-the week and the higher temperature has triggered the human body to have heuristically biased in decision-making. When people are in a happy mood, their judgment would be more positive as compared to sad mood. In addition, Hirshleifer and Shumway (2003) also provided evidence that weather affects the investors as well as the stock return. They found that stock returns are significantly higher on sunny days than on rainy days. Saunders (1993) has shown that cloud cover has a negative impact on the US stock returns. However, Denissen et al. (2008) argued that a good weather will not bring pleasant moods to an individual instead the weather variables like sunlight, wind power and temperature appeared to have negative effects on the human mood.

Although there have been voluminous studies examining the impact of weather on stock returns in both developed and emerging markets, the mixed results are reported. Some studies found the existence of positive relationship between weather and stock returns (see Dowling \& Lucey, 2005) while some observed a negative relationship between weather and stock returns (see Shu \& Hung, 2009; Floros, 2011; Yoon \& Kang, 2009; Cao \& Han, 2015). There are also studies show evidence of no significant relationship between the variables (see Keef \& Roush, 2007; Saporoschenko, 2011; Wang et al. 2011). In the context of Argentina, there are still limited number of studies documented on this issue. Giovanis (2009) only focuses on the monthly effect in the stock market of Argentina while Rodriguez (2012) and Dumitriu and Stefanescu (2013) have examined the day of the week effect. Argentina is 
ranked the first place in the top seven hottest stock markets in 2015. Although the economic growth of Argentina has not been performing well but the stock market is blooming in 2014. CNN news reported that the Argentina stock market provides $37 \%$ of return for half year in 2015 . Therefore, this study attempts to investigate the relationship between weather (temperature, humidity and wind) and stock returns in Argentina. We hope to contribute further to the body of knowledge by providing some new light on this issue.

The rest of this paper is organized as follows. In the next section, we discuss some selected literature review. Section 3 provides the empirical framework and data. Section 4 provides empirical findings while in the last section we provide some conclusion and implications.

\section{Literature Review}

According to Bechara and Damasio (2005), neuroscience and economics are related to each other especially in the stage of decision-making. They argued that merely using knowledge and reasoning are not adequate for making favourable decisions and the importance of emotion should be stressed on as emotion could benefit or disrupt the decision made. When people are in a happy mood, their judgment would be more positive as compared to sad mood. Moods can highly affect decision making in the stock market. Anderson (1989) argued that human tends to become more aggressive in hot temperature. His findings show that the level of aggression increased in hotter regions and in hotter periods of time, there are more aggressive behaviours like riots, wife beatings, rapes and even murders. In addition, Sinclair and Mark (1995) argued that human in good moods will rely much on heuristics and this will lead to less precise, evaluative and analytical when dealing with information presented to them. The accuracy of judgment made on the information will be less effective when a same situation is given to them in a bad mood.

Moreover, Howarth and Hoffman (1984) indicate that weather has an impact on optimism. The optimism scores increased as sunshine hours increased. This indicates that human is more optimism when exposed to sunshine. However, an opposite results obtained by Denissen et al. (2008) which show that there is no significant relationship between weather and positive effect. In their study, a good weather will not bring pleasant moods to an individual. On the other hand, they found that weather variables like sunlight, wind power and temperature appeared to have an impact on negative effects of human mood.

Hirshleifer and Shumway (2003) found that the weather affects the stock market returns in 26 countries. Their findings show that the market tends to go up during sunny days in the city. There is existence of an upbeat mood with sunny weather. However, Chang et al. (2006) found that when the weather is at extreme no matter is hot or cold, the stock returns tend to be low for the case of Taiwan. This is supported by Wang et al. (2011) they also found that temperature is insignificant towards stock return in Taiwan.

Another study by Brahmana et al. (2012) found that there is existence of day-of-week-anomaly (DOWA) in Indonesia. Their results show that the returns for Tuesday, Wednesday, Thursday and Friday are generally positive while only Monday is negative. The relationship between temperature and market return is insignificant. In other words, weather effect is not present in Indonesia's market return. Using the same method, Brahmana et al. (2014) found that there is Monday irrationality in Malaysia as the temperature on Monday is averagely higher than other days of the week. Hence, there is a negative relationship between Monday's temperature on stock returns. Thus, the higher the temperature, the lower the stock returns.

For the case of Korea, Yoon and Kang (2009) found evidence that temperature is negatively significant towards stock returns. The higher the temperature, the lower the stock returns. Furthermore, Floros (2011) also found a negative relationship between stock return and temperature in the Portuguese stock market. In addition, the findings also show the existence of January effect. The winter season of Portugal falls in the month of January, hence they believed that it is the low temperature that leads to higher returns in January as compared to any other months in the year.

\section{Data Preliminaries and Empirical Framework}

\subsection{Data Preliminaries}

The sample data used in this study are the daily market stock indexes of Argentina which is the MERVAL Index. The period for the study is 15 years which is from 2001 to 2014. The daily stock prices are retrieved from Yahoo Finance and then, we compute the daily returns. The daily weather data are temperature (TEMP), humidity (HUM) and wind (WIND) for the capital city of Argentina, Buenos Aires. The temperature is measured in degree Celsius $\left({ }^{\circ} \mathrm{C}\right)$, humidity in percentage $(\%)$ and wind in kilometre per hours $(\mathrm{km} / \mathrm{h})$. All the weather data are retrieved from the Weather Underground. 


\subsection{Empirical Models}

Similar with many previous studies, we also use regression models to examine the relationship between weather and stock returns. The general model is as follows:

$$
R_{t}=\alpha+\beta_{1} T E M P+\beta_{2} H U M+\beta_{3} W I N D+\varepsilon_{t}
$$

Where

$\mathrm{Rt}=$ Stock returns

TEMP $=$ Temparature

HUM = Humidity

WIND $=$ Wind

$\varepsilon=$ error term

We use the following model to examine the existence of day-of-the-week anomal (DOWA) effect:

$$
R_{t}=\beta_{1} D_{\text {Mon }}+\beta_{2} D_{\text {Tue }}+\beta_{3} D_{\text {Wed }}+\beta_{4} D_{\text {Thu }}+\beta_{5} D_{F r i}+\varepsilon_{t}
$$

Next, the equation below is to test on the Monday effect:

$$
R_{t}=\alpha+\beta_{1} D_{\text {Tue }}+\beta_{2} D_{\text {Wed }}+\beta_{3} D_{\text {Thu }}+\beta_{4} D_{\text {Fri }}+\varepsilon_{t}
$$

For equation 2 and 3, $D_{\text {Mon }}, D_{\text {Tue }}, D_{\text {Wed }}, D_{\text {Thu }}$ and $D_{\text {Fri }}$ are Monday Dummy, Tuesday Dummy, Wednesday Dummy, Thurday Dummy and Friday Dummy respectively. $\beta_{1}, \beta_{2}, \beta_{3}, \beta_{4}$ and $\beta_{5}$ denotes the mean return of Monday, Tuesday, Wednesday, Thursday and Friday.

Then, we use the following models to investigate the interaction of DOWA effect with temparature, humidity and wind variables.

$$
\begin{aligned}
& R_{t}=\beta_{1} \text {TEMP }_{1} * D_{1}+\beta_{2} \text { TEMP }_{2} * D_{2}+\beta_{3} \text { TEMP }_{3} * D_{3}+\beta_{4} \text { TEMP }_{4} * D_{4}+\beta_{5} \text { TEMP }_{5} * D_{5}+\varepsilon_{t} \\
& R_{t}=\beta_{1} \text { HUM }_{1} * D_{1}+\beta_{2} \text { HUM }_{2} * D_{2}+\beta_{3} \text { HUM }_{3} * D_{3}+\beta_{4} H_{4} M_{4} * D_{4}+\beta_{5} H U M_{5} * D_{5}+\varepsilon_{t} \\
& R_{t}=\beta_{1} \text { WIND }_{1} * D_{1}+\beta_{2} \text { WIND }_{2} * D_{2}+\beta_{3} \text { WIND }_{3} * D_{3}+\beta_{4} \text { WIND }_{4} * D_{4}+\beta_{5} \text { WIND }_{5} * D_{5}+\varepsilon_{t}
\end{aligned}
$$

\section{Empirical Findings}

\subsection{Descriptive Statistics}

Table 1. Market Returns, Temperature, Humidity and Wind

\begin{tabular}{lcccc}
\hline & $\begin{array}{c}\text { Market Returns } \\
(\%)\end{array}$ & $\begin{array}{c}\text { Temperature } \\
\left({ }^{\circ} \mathrm{c}\right)\end{array}$ & $\begin{array}{c}\text { Humidity } \\
(\%)\end{array}$ & $\begin{array}{c}\text { Wind } \\
(\mathrm{km} / \mathrm{h})\end{array}$ \\
\hline Mean & 0.116348 & 17.86295 & 70.79703 & 15.87421 \\
Median & 0.123984 & 18.00000 & 71.00000 & 14.00000 \\
Maximum & 17.48789 & 33.00000 & 100.0000 & 47.00000 \\
Minimum & -12.14797 & 1.000000 & 27.00000 & 3.000000 \\
Standard & 2.203274 & 5.371235 & 12.23994 & 6.136685 \\
Deviation & & & &
\end{tabular}

Table 1 shows the average market returns, temperature, humidity and wind are $0.1163 \%, 17.86^{\circ} \mathrm{c}, 70.80 \%$ and $15.87 \mathrm{~km} / \mathrm{h}$ respectively. Throughout the 15 years, the highest return was $17.49 \%$, while the lowest return was at $-12.15 \%$. Temperature reached maximum at $33^{\circ} \mathrm{c}$ and minimum at $1{ }^{\circ} \mathrm{c}$. Humidity shows a tremendous difference among the highest (100\%) and lowest value (27\%) which is $73 \%$. The difference between the highest and lowest value for wind is $44 \mathrm{~km} / \mathrm{h}$. The standard deviation for market returns, temperature, humidity and wind are 2.203, $5.371,12.23$ and 6.137 respectively. 
Table 2. Market Returns for Days of the Week

\begin{tabular}{lccccc}
\hline $\begin{array}{l}\text { Market } \\
\text { Returns }\end{array}$ & Monday & Tuesday & Wednesday & Thursday & Friday \\
\hline Minimum & -10.7314 & -10.9905 & -12.1479 & -8.3873 & -7.8231 \\
Maximum & 13.4238 & 10.9951 & 9.5805 & 17.4878 & 11.7618 \\
$\begin{array}{l}\text { Mean } \\
\begin{array}{l}\text { Standard } \\
\text { deviation }\end{array}\end{array}$ & -0.0272 & 0.0667 & 0.1926 & 0.1454 & 0.2013 \\
\hline
\end{tabular}

Table 2 shows the minimum, maximum, average dan standard deviation of market returns. We observed that only Monday has a negative average return whereas all the other days in the week show positive average returns. The average return was highest on Friday $(0.2013 \%)$, followed by Wednesday $(0.1926 \%)$, Thursday $(0.1454 \%)$, Tuesday $(0.0668 \%)$, and the lowest on Monday $(-0.0272 \%)$. The findings of negative return on Monday are in line with Silva (2010), Lean and Tan (2010), Muhammad and Rahman (2010), Haroon and Shah (2013) and Brahmana et. al (2012)

Table 3. Correlation between Market Returns, Temperature, Humidity and Wind.

\begin{tabular}{lcccc}
\hline & Market Return & Temperature & Humidity & Wind \\
\hline Market Return & 1.0000 & & & \\
Temperature & 0.0323 & 1.0000 & & \\
Humidity & -0.0204 & -0.0574 & 1.0000 & \\
Wind & -0.0006 & 0.0074 & -0.0321 & \multirow{2}{*}{1.0000} \\
\hline
\end{tabular}

Table 3 reports the correlation analysis of the variables. The highest correlation pair is between temperature and humidity at -0.0574 . The lowest coefficient correlation is between market return and wind at -0.0006 . It seems that only temperature has positive and high correlation with the market return at 0.0323 compared to humidity and wind.

\subsection{Regression Model Results}

The results from regression in Table 4 show that only temperature is positive and significant influencing the market returns. Both humidity and wind are insignificant. The results of positive impact of temparature towards stock returns are in line with Hirshleifer and Shumway (2003) and Brahmana et. al (2014). For example, Hirshleifer and Shumway (2003) found evidence that stock returns are significantly higher on sunny days than on rainy days. Brahmana et. al (2014) note that high temperature has triggered the human body to have heuristically biased in decision-making because they are in a happy mood. Their judgment would be more positive as compared to sad mood.

In addition, Keef and Roush (2007) and Saporoschenko (2011) also found that the wind is not significant towards stock return. However, the results are conflicting with Yoon and Kang (2009), Floros (2011) and Brahmana et al. (2012) that have proven that temperature has negative relationship with stock returns. Moreover, Yoon and Kang (2009), Tuna (2014) and Cao and Han (2015) have found significant relationship of humidity with stock returns. Our findings show evidence that stock return is positively affected by temperature. Our finding suggested that the higher the temperature, the higher the stock returns. The low value of our R-squared is in line with previous studies such as Loughran and Schultz (2003), Ashikh (2012) and Cao and Han (2015). 
Table 4. Regression Results (Dependent variable: Market Returns)

\begin{tabular}{lllll}
\hline Variables & Coefficient & Standard Error & t-statistic & Probability \\
\hline Temperature & 0.012849 & 0.006808 & 1.887202 & $0.0592^{*}$ \\
Humidity & -0.003360 & 0.002989 & -1.123937 & 0.2611 \\
Wind & -0.000537 & 0.005952 & -0.090200 & 0.9281 \\
Constant & 0.133206 & 0.271891 & 0.489926 & 0.6242 \\
R-squared & 0.001396 & & & \\
Adjusted & 0.000573 & & & \\
R-squared & & & & \\
F-statistic & 1.695277 & & & \\
Probability & 0.165821 & & & \\
(F-statistic) & & & & \\
\hline
\end{tabular}

Note: * denotes significance at $10 \%$ level.

\subsection{Day of Week Effect}

Table 5 shows the results of day-of-week effect in the Argentina's stock market. We find that the coefficient of Monday is negative but not significant. The coefficients of Tuesday, Wednesday, Thursday and Friday all show positive signs which demonstrate that there are positive returns on Tuesday, Wednesday, Thursday and Friday. Friday has the highest coefficient of 0.2011 compared to the other days, and this indicates that Friday has the highest return. The results are in line with $\mathrm{Gu}$ (2005) where he also provided evidence of mean Friday returns are the highest in the China's stock markets. In addition, $\mathrm{Gu}$ (2004) also noted that there have been numerous studies also have reported abnormally high average Friday returns and significantly negative average Monday returns in the US stock markets.

Table 5. Day-of-Week Effect

\begin{tabular}{lllll}
\hline Variable & Coefficient & Standard Error & t-statistic & Probability \\
\hline Monday & -0.027064 & 0.084169 & -0.321538 & 0.7478 \\
Tuesday & 0.065897 & 0.080709 & 0.816476 & 0.4143 \\
Wednesday & 0.186869 & 0.080493 & 2.321563 & $0.0203^{* *}$ \\
Thursday & 0.145044 & 0.081256 & 1.785033 & $0.0743^{*}$ \\
Friday & 0.201070 & 0.082098 & 2.449152 & $0.0144^{* *}$ \\
R-squared & 0.001425 & & & \\
Adjusted & 0.000326 & & & \\
R-squared & & & & \\
\hline
\end{tabular}

Note: $*$ and $* *$ denote significance at $10 \%$ and $5 \%$ levels respectively.

\subsection{Monday Effect}

Next, Table 6 shows that the coefficient of Tuesday, Wednesday, Thursday and Friday are positive and this denotes that there is a greater return of these days than Monday. Only Wednesday and Friday are found to be significant at $10 \%$. Wednesday has greater return than Monday for about 0.21 times whereas Friday return is 0.23 times greater than Monday return. Therefore, to some extend, we could conclude that there exist Monday effect in the Argentina's stock market. Our findings are in line with Silva (2010), Brahmana et. al (2012), and Georgantopoulos and Tsamis (2013) that also found highest return on Friday and lowest return on Monday. 
Table 6. Monday effect

\begin{tabular}{lrrrr}
\hline Variable & \multicolumn{1}{c}{ Coefficient } & Standard Error & \multicolumn{1}{c}{ t-statistic } & \multicolumn{1}{c}{ Probability } \\
\hline Tuesday & 0.090192 & 0.116304 & 0.775482 & 0.4381 \\
Wednesday & 0.211164 & 0.116155 & 1.817958 & $0.0692^{*}$ \\
Thursday & 0.169339 & 0.116685 & 1.451257 & 0.1468 \\
Friday & 0.225365 & 0.117273 & 1.921720 & $0.0547^{*}$ \\
Constant & -0.024295 & 0.083742 & -0.290120 & 0.7717 \\
R-squared & 0.001419 & & & \\
Adjusted & 0.000321 & & & \\
R-squared & & & & \\
F-statistic & 1.292158 & & & \\
Probability & 0.270648 & & & \\
(F-statistic) & & & & \\
\hline
\end{tabular}

Note: *denotes significance at $10 \%$ level.

\subsection{Weather and DOWA}

Table 7 shows the results of interactions relationship between weather on day-of-the week and stock market returns. The results indicate that temperature on Wednesday, Thursday and Friday are siginificant affecting the stock market returns. This indicates that the higher the temperature, the higher the return. In terms of humidity, all coeefficients are positive. However, only Monday, Wednesday and Thursday are found to be significant. In addition, we also find the significant of wind on Wednesday and Friday towards stock market returns. Therefore, we conclude that all three weather variables appeared to have relationship with the stock returns on few trading days. Temparature, Humidity and Wind on Wednesday seems to be significant influencing stock market returns in Argentina. Consistent with Dowling and Lucey (2005), wind is found to be positive in all days of the week. However, Yoon and Kang (2009), Tuna (2014) and Cao and Han (2015) suggested negative relationship between humidity and stock returns.

Table 7. Temperature and DOWA

\begin{tabular}{lccc}
\hline Variable & TEMPARATURE & HUMIDITY & WIND \\
\hline \multirow{2}{*}{ Monday } & -0.000154 & 0.002374 & -0.000197 \\
& $(0.9727)$ & $\left(0.0447^{* *}\right)$ & $(0.9681)$ \\
Tuesday & 0.004602 & 0.000947 & 0.004101 \\
& $(0.2891)$ & $(0.3976)$ & $(0.3916)$ \\
Wednesday & 0.009795 & & 0.002045 \\
& $\left(0.0227^{* *}\right)$ & $\left(0.0675^{*}\right)$ & 0.008404 \\
Thursday & 0.010420 & & $(0.0739 *)$ \\
& $\left(0.0166^{* *}\right)$ & 0.001933 & 0.006379 \\
Friday & 0.010190 & $(0.0870 *)$ & $(0.1867)$ \\
R-squared & $\left(0.0209^{* *}\right)$ & 0.001050 & 0.012730 \\
\hline
\end{tabular}

Note: $*, * *$ and $* * *$ denotes significance at $10 \%, 5 \%$ and $1 \%$ levels respectively. Figure in brackets refers to p-values. 


\section{Conclusion}

The main objective of this study is to examine is the presence of weather effects in the Argentina's stock market. The sample period for this study is from 2001 to 2014. The data consists of stock market returns, temperature, humidity and wind. We find evidence of the existence of day-of-week effect in the Argentina's stock market. On average, highest return falls on Friday and lowest return falls on Monday. The overall results show that all weather variables such as temperature, humidity and wind appeared to have significant relationship with stock market returns in some of the trading days in the week. To some extent, we can conclude that among all the weather variables, temperature is considered very significant in influencing the stock market returns in Argentina. Our findings suggest that the stock market returns are higher when the temperature is higher. This phenomenon is related to the seasonal affective disorder (SAD). When temperature is low, people tend to feel upset, moody and they become inactive. On the contrary, when temperature is high, people become active, in a good mood and they are motivated and optimistic to trade actively in the stock market. Saunders (1993) and Hirshleifer and Shumway (2003) argued that the behaviour of investors/ market traders are likely to be affected by the weather and later it is likely reflected in stock returns. In addition, Chang et al. (2006) noted that temperature has strong threshold effects on stock market returns. Since the results provide empirical evidence that weather is very significant influencing the stock market returns, thus we can conclude that stock market of Argentina is not informational efficient. The results have major implications for traders, individual investors, fund managers and financial institutions planning to make investment in the Argentina's stock market.

This study has limitations as it only focuses on the relationship between weather and stock market returns for the case of Argentina. Future research can include more countries with different regions and climates. In addition, future research also can explore into the possibility of how weather information is transmitted across the nations. This shall enrich the literature on this subject matter.

\section{References}

Anderson, C.A. (1989). Temperature and aggression: Ubiquitous effects of heat on occurrence of human violence. Psychological Bulletin, 106(1), 74-96. https://doi.org/10.1037/0033-2909.106.1.74

Bechara, A. \& Damasio, A.R. (2005). The somatic marker hypothesis: A neural theory of economic decision. Games and Economic Behavior, 52(2), 336-372. https://doi.org/10.1016/j.geb.2004.06.010

Brahmana, R., Hooy, C. W., \& Ahmad, Z. (2012). Weather, investor irrationality and day-of-the-week anomaly: Case of Indonesia. Journal of Bioeconomics, 14(2), 129-146. https://doi.org/10.1007/s10818-011-9107-z

Brahmana, R., Hooy, C. W., \& Ahmad, Z. (2014). The role of weather on investors“ Monday irrationality: Insights from Malaysia. Contemporary Economics, 8(2), 175-190. https://doi.org/10.5709/ce.1897-9254.139

Cao, G. X., \& Han, Y. (2015). Does the weather affect the Chinese stock markets? Evidence from the analysis of DCCA cross-correlation coefficient. International Journal of Modern Physics B, 29(1), 1-23. https://doi.org/10.1142/S0217979214502361

Chang, T. Y., Nieh, C. C., Yang, M. J., \& Yang, T. Y. (2006). Are stock market returns related to the weather effects? Empirical evidence from Taiwan. Physica A, 364, 343- 354. https://doi.org/10.1016/j.physa.2005.09.040

Congressional Research Service (2015). Argentina: Background and U.S. Relations. Retrieved from https://www.fas.org/sgp/crs/row/R43882.pdf

Denissen, J. J. A., Butalid, L., PenkeL., \& Aken, M. A. G. (2008). The effects of weather on daily mood: A multilevel approach. Emotion, 8(5), 662-667. https://doi.org/10.1037/a0013497

Dowling, M., \& Lucey, B. M. (2005). Weather, biorhythms, beliefs and stock. International Review of Financial Analysis, 14(3), 337-355. https://doi.org/10.1016/j.irfa.2004.10.003

Dumitriu, R., \& Stefanescu, R. (2013). DOW effects in returns and in volatility of stock markets during quiet and turbulent times. Proceedings of the 5th International Conference on Economics and Administration (pp. 143-169). Bucharest, Romania: University of Bucharest. https://doi.org/10.2139/ssrn.2225937

Floros, C. (2011). On the relationship between weather and stock market returns. Economics and Finance, 28(1), 5-13. https://doi.org/10.1108/10867371111110525

Georgantopoulos, A.G., Kenourgios, D.F. \& Tsamis, A.D. Calendar Anomalies in Emerging Balkan Equity Markets. International Economics and Finnace Journal, 6(1), 67-82.

Giovanis, E. (2009). The month-of-the-year effect: Evidence from GARCH models in fifty five stock markets. Global Journal of Finance and Management, 1(2), 75-98. https://doi.org/10.2139/ssrn.1595706 
Gu, A.Y. (2004). The Reversing Weekend Effect: Evidence from the U.S. Equity Markets. Review of Quantitative Finance and Accounting, 22, 5-14. https://doi.org/10.1023/B:REQU.0000006183.42549.50

Gu, A.Y. (2005). Day-of-the-Week and Month-of-the-year Effect in China's Stock Markets and Related Factors. Academy of Accounting and Financial Studies Journal, 9(2), 33-46.

Haroon, A. M., \& Shah. N. (2013). Investigating day-of-the-week effect in stock returns: Evidence from Karachi stock exchange-Pakistan. Pakistan Journal of Commerce and Social Sciences, 7(2), 381-393.

Hirshleifer, D., \& Shumway, T. (2003). Good day sunshine: Stock returns and the weather. The Journal of Finance, 58(3), 1009-1032. https://doi.org/10.1111/1540-6261.00556

Howarth, E., \& Hoffman, M. S. (1984). A multidimensional approach to the relationship between mood and weather. British Journal of Psychology, 75(1), 15-23. https://doi.org/10.1111/j.2044-8295.1984.tb02785.x

Isen, A. M. (2001). An influence of positive affect on decision making in complex situations: Theoretical issues with practical implications. Journal of Consumer Psychology, 11(2), 75-85. https://doi.org/10.1207/S15327663JCP1102_01

Keef, S. P., \& Roush, M. L. (2007). Daily weather effects on the returns of Australian stock indices. Applied Financial Economics, 17(3), 173-184. https://doi.org/10.1080/09603100600592745

Lean, H. H., \& Tan, V. K. M. (2010). Existence of the day-of-week effect in FTSE Bursa Malaysia. Jurnal Pengurusan, 31, 3-11.

Loughran, T., \& Schultz, P. (2004). Weather, Stock Returns, and the Impact of Localized Trading Behavior. Journal of Financial and Quantitative Analysis, 39(2), 343-364. https://doi.org/10.1017/S0022109000003100

Muhammad, N. M. N., \& Rahman, N. M. N. A. (2010). Efficient market hypothesis and market anomaly: Evidence from day-of-the week effect of Malaysian exchange. International Journal of Economics and Finance, 2(2), 35-42. https://doi.org/10.5539/ijef.v2n2p35

Rodriguez, W. K. (2012). Day of the week effect in Latin American stock markets. Revista de Analisis Economico, 27(1), 71-89. https://doi.org/10.4067/S0718-88702012000100004

Saporoschenko, A. (2011). The effect of Santa Ana wind conditions and cloudiness on Southern California stock returns. Applied Financial Economics, 21(10), 683-694. https://doi.org/10.1080/09603107.2010.535785

Saunders, E.M. (1993). Stock prices and Wall Street weather American Economics Review, 83(5), 1337-1345

Shu, H. C., \& Hung, M. W. (2009). Effect of wind on stock market returns: Evidence from European markets. Applied Financial Economics, 19(11), 893-904. https://doi.org/10.1080/09603100802243766

Silva, P. (2010). Calendar -anomalies\| in the Portuguese stock market. Investment Analysts Journal, 71, 37-50. https://doi.org/10.1080/10293523.2010.11082518

Sinclair, R. C., \& Mark, M. M. (1995). The effects of mood state on judgemental accuracy: Processing strategy as a mechanism. Cognitive and Emotion, 9(5), 417-438. https://doi.org/10.1080/02699939508408974

Tuna (2014). Analyzing weather effect on Istanbul Stock Exchange: An empirical analysis for 1987-2006 period. Economics and Finance Review, 3(8), 17-25.

Wang, Y.H., Lin, C.T. \& Lin, J.D. (2011). Does weather impact the stock market? Empirical evidence in Taiwan. Quality \& Quantity, 46(2), 695-703. https://doi.org/10.1007/s11135-010-9422-9

Yoon and Kang (2009). Weather effects on returns: Evidence from the Korean stock market. Physica A: Statistical Mechanics and its Application, 388(5), 682- 690. https://doi.org/10.1016/j.physa.2008.11.017 